\title{
MANAJEMEN RISIKO PROSES PRODUKSI GULA DENGANMETODE FAILURE MODE EFFECT AND ANALYSIS
}

\author{
Mila Faila Sufa"1), Umi Khoiriyah ${ }^{2)}$ \\ Jurusan Teknik Industri, Fakultas Teknik, Universitas Muhammadiyah Surakarta \\ Pusat Studi Logistik dan Optimisasi Industri, Universitas Muhammadiyah Surakarta \\ Jl. A. Yani Tromol Pos 1 Pabelan Kartasura 57102
}

\begin{abstract}
A company should pay attention to operational risk to maximise its efficiency and effectivity. Identification of failure and the cause and the impact of the failure at milling station is needed to be done so that the sugar production process can run well. Here, we employ a failure mode and effect analysis to identify the failure and its effect. We obtain 22 operational risks with two critical risks. The two critical risks are then used as top event in analysing the cause of the failure. The result from fault tree analysis shows that there are 4 basic events, which are the turbine vibrates, schedule part's change before failure, high rainfall and the schedule and priority of processing.
\end{abstract}

Keywords : event, failure, operational risk, fault tree analysis and failure mode and effect analysis

\section{Pendahuluan}

Pabrik Gula Jatiroto merupakan salah satu perusahaan pengolahan tebu yang terletak di Lumajang dan berada dibawah naungan PT Perkebunan Nusantara XI dengan kantor pusat yang berada di Surabaya. Terdapat tahapan-tahapan yang harus dilalui dalam pengolahan gula, berawal dari tahap penyiapan, pencacahan, pemerahan, pemurnian, penguapan, kristalisasi, putaran, pengepakan dan berakhir pada penyimpanan. Gula yang dihasilkan di PG Jatiroto merupakan gula dengan kualitas Superieur Hoofd Suiker (SHS).Persediaan tebu sangat berpengaruh dalam proses produksi, apabila persediaan tebu terhambat maka mengakibatkan proses produksi berhenti. Oleh karena itu persediaan bahan baku tebu pada emplasmen sangat perlu diperhatikan agar dapat memenuhi kapasitas giling tiap harinya. Pengendalian kualitas menjadi salah satu hal terpenting untuk menghasilkan gula yang berkualitas. Dalam tahapan proses produksi terdapat gangguangangguan operasional seperti kerusakan mesin, human error, atau masalah dari luar pabrik seperti kedatangan bahan baku yang terlambat. Kerusakan alat produksi akan menimbulkan adanya potensi risiko operasional. Risiko-risiko tersebut harus dapat di identifikasi dan dikelolah secara serius untuk terciptanya kestabilan dalam proses produksi.Kesehatan keselamatan kerja juga perlu diperhatikan agar mengurangi risiko operasional. Semakin efisian operasional pabrik gula maka akan didapatkan hasil gula yang maksimal. Proses awal dari proses pembuatan gula berada di stasiun gilingan. Stasiun gilingan (pemerahan) bertujuan pemisahan nira dengan ampas tebu. Apabila terdapat masalah pada salah satu alat penunjang dalam proses penggilingan dapat berakibat buruk pada proses produksi berikutnya. Namun, kesalahan tidak hanya mungkin terjadi murni karena alat penunjang, tidak jarang human error juga menjadi salah satu penyebab masalah dalam produksi. Kapasitas gilingan juga perlu diperhatikan dikarenakan apabila ampas melebihi kapasitas mesin gilingan, maka akan mengakibatkan jubel ampas pada alat gilingan dan overload pada turbin. Kerusakan-kerusakan yang terjadi akan mengakibatkan risiko operasional yang akan berakibat tertundanya waktu produksi. Untuk menganalisis risiko operasional dalam sistem produksi pabrik gula maka diperlukan pengamatan, wawancara, dan document review untuk mengetahui penyebab kegagalan tersebut.

\footnotetext{
*Correspondance : Mila.Faila.Sufa@ums.ac.id
} 


\section{Metode}

Dalam merancang sistem produksi yang efektif dan efisien, sangat penting untuk menerapkan manajemen risiko didalamnya. Manajemen risiko adalah suatu pendekatan yang mengadopsi sistem yang konsisten untuk mengelola semua risiko yang dihadapi oleh perusahaan (Tjahjadi, 2011).Identifikasi risiko operasional yang berakibat terganggunya proses produksi dapat dilakukan dengan document review dan teknik wawancara. Risiko-risiko tersebut kemudian diolah dan dianalisis penyebabnya dengan menggunakan metode Failure Mode and Effect Analysis (FMEA). Dari perhitungan Risk Priority Number (RPN) pada metode FMEA, kemudian resiko kritis yang didapatkan digunakan sebagai top event dalam analisis akar penyebab risiko (basic event) dengan menggunakan Fault Tree Analysis (FTA).Selanjutnya dilakukan analisis terhadap risiko kritis beserta basic event dan usulan mitigasi resiko.

\section{Hasil dan Pembahasan}

Proses identifikasi risiko operasional pada stasiun gilingan dilakukan dengan teknik document review pada buku laporan produksi harian, pengamatan lapangan dan wawancara pada operator mesin.Identifikasi risiko operasional kali ini terfokuskan pada stasiun gilingan. Dimana data yang digunakan data-data yang mengakibatkan berhentinya proses produksi pada PG Jatiroto. Identifikasi risiko-risiko operasional merupakan teknik dalam tercapainya manajemen operasional yang efektif dan efisien.Risk Priority Number (RPN) yang didapat dari hasil perkalian Severity,Occurance, Detection dan mengetahui penyebab potensi kegagalan.

Tingkat Keparahan (Severity) adalah penilaian terhadap keseriusan dari akibat yang ditimbulkan. Dalam arti setiap kegagalan yang timbul akan dinilai seberapa besarkah tingkat keseriusannya. Terdapat hubungan secara langsung antara akibat dan severity. Sebagai contoh, apabila akibat yang terjadi adalah akibat yang kritis, maka nilai severity pun akan tinggi. Dengan demikian, apabila akibat yang terjadi bukan merupakan akibat yang kritis, maka nilai severity pun akan sangat rendah. Tingkat Kejadian (Occurance) adalah kemungkinan bahwa penyebab tersebut akan terjadi dan menghasilkan bentuk kegagalan selama masa penggunaan produk. Occurance merupakan nilai rating yang disesuaikan dengan frekuensi yang diperkirakan dan atau angka kumulatif dari kegagalan yang dapat terjadi.Nilai Detection diasosiasikan dengan pengendalian saat ini.Detectionadalah pengukuran terhadap kemampuan mengendalikan / mengontrol kegagalan yang dapat terjadi.PG Jatiroto menggunakan 3 penggerak gilingan. Gilingan pertama sampai ke empat menggunakan turbin uap, hagglund hidrolik untuk gilingan lima dan motor listrik untuk gilingan 6. Setiap gilingan terdiri dari 3 buah rol. Ketiga rol gilingan dikenal sebagai rol atas, rol depan, dan rol belakang. Pada gilingan ke enam terdapat 6 rol (sixroll).Penggunaan sixroll diharapkan agar pemerahan nira dapat dilakukan secara lebih maksimal.Elevator yang dilengkapi dengan cakar digunakan untuk membawa ampas atau biasa disebut dengan IMC. Elevator digerakkan oleh gilingan menggunakan roda gigi atau sprocket dan rantai.

Perhitungan Risk Priority Number (RPN) akan lebih mudah ketika terdapat skalar parameter dalam pengambilan keputusan. Skalar yang digunakan dapat dilihat pada tabel-tabel dibawah ini. Hasil identifikasi potensi risiko pada stasiun gilingan dapat dilihat pada tabel 4 .

Tabel 1. Tabel Skalar Parameter Severity

\begin{tabular}{|c|l|l|}
\hline Skalar & \multicolumn{1}{|c|}{ Parameter } & \multicolumn{1}{c|}{ Deskripsi } \\
\hline 1 & Tidak Signifikan & Waktu henti $<5$ menit \\
\hline 2 & Kecil & Waktu henti $5-10$ menit \\
\hline 3 & Sedang & Waktu henti $10-30$ menit \\
\hline 4 & Besar & Waktu henti $30-60$ menit \\
\hline 5 & Sangat Signifikan & Waktu henti $>60$ menit \\
\hline
\end{tabular}


Tabel 2. Tabel Skalar Parameter Occurance

\begin{tabular}{|c|l|l|}
\hline Skalar & \multicolumn{1}{|c|}{ Parameter } & \multicolumn{1}{|c|}{ Deskripsi } \\
\hline 1 & Jarang Terjadi & Frekuensi 1 -3 kali \\
\hline 2 & Agak Jarang Terjadi & Frekuensi 4 -6 kali \\
\hline 3 & Mungkin Terjadi & Frekuensi 7 - 10 kali \\
\hline 4 & Sering terjadi & Frekuensi 10 - 20 kali \\
\hline 5 & Hampir Pasti Terjadi & Frekuensi > 20 kali \\
\hline
\end{tabular}

Tabel 3. Tabel Skalar Parameter Detection

\begin{tabular}{|c|l|l|}
\hline Skalar & \multicolumn{1}{|c|}{ Parameter } & \multicolumn{1}{c|}{ Deskripsi } \\
\hline 1 & Sangat Cepat & Waktu deteksi $0-5$ detik \\
\hline 2 & Cepat & Waktu deteksi 6-10 detik \\
\hline 3 & Cukup & Waktu deteksi $11-30$ detik \\
\hline 4 & Lama & Waktu deteksi $30-60$ detik \\
\hline 5 & Sangat Lama & Waktu deteksi $>60$ detik \\
\hline
\end{tabular}

Tabel 4. Hasil Perhitungan RPN

\begin{tabular}{|c|l|c|c|c|c|}
\hline No & Resiko Operasional & Severity & Occurance & Detection & RPN \\
\hline 1 & Turbin gilingan overload & 3 & 5 & 2 & 30 \\
\hline 2 & Penambahan ganjal gilingan & 4 & 1 & 3 & 12 \\
\hline 3 & Kerusakan pada turbin & 5 & 3 & 3 & 45 \\
\hline 4 & Elevator overload & 3 & 4 & 2 & 24 \\
\hline 5 & Kapasitas uap tidak mencukupi & 2 & 5 & 1 & 10 \\
\hline 6 & Kancing elevator lepas & 2 & 2 & 2 & 8 \\
\hline 7 & Tebu terlambat datang & 5 & 5 & 2 & 50 \\
\hline 8 & Gangguan tombol kontrol IMC & 2 & 1 & 2 & 4 \\
\hline 9 & Motor listrik mati & 4 & 4 & 1 & 16 \\
\hline 10 & Kebakaran dibawah motor & 5 & 1 & 3 & 15 \\
& sixroll & & & & \\
\hline 11 & Sixroll trip & 5 & 3 & 2 & 30 \\
\hline 12 & Bongkar pasang talang luncur & 4 & 3 & 2 & 24 \\
\hline 13 & Rantai elevator putus & 3 & 3 & 3 & 27 \\
\hline 14 & Kerusakan pada cakar & 4 & 2 & 2 & 16 \\
\hline 15 & Stang skraper putus & 2 & 3 & 1 & 6 \\
\hline 16 & Hagglund mati & 3 & 1 & 3 & 9 \\
\hline 17 & Kerusakan sprocket & 3 & 2 & 2 & 8 \\
\hline 18 & Pompa gilingan trip & 3 & 4 & 2 & 6 \\
\hline 19 & Baut formil lepas & & 2 & 2 & 8 \\
\hline 20 & Trafo overload & 3 & & 24 \\
\hline 21 & Pen mil lepas & 2 & 2 & \\
\hline 22 & Rantai penggerak BEC putus & 3 & 2 & 2 \\
\hline & & 3 & 3 & 2 & 2 \\
\hline
\end{tabular}


Dari tabel perhitungan diatas dapat diketahui risiko operasional dengan nilai kritis tinggi berada pada kerusakan turbin dan tebu terlambat datang. Kemudian risiko kritis yang diidentifikasi akan digunakan sebagai top event dalam analisis akar penyebab risiko (basic event) dengan menggunakan Fault Tree Analysis (FTA)

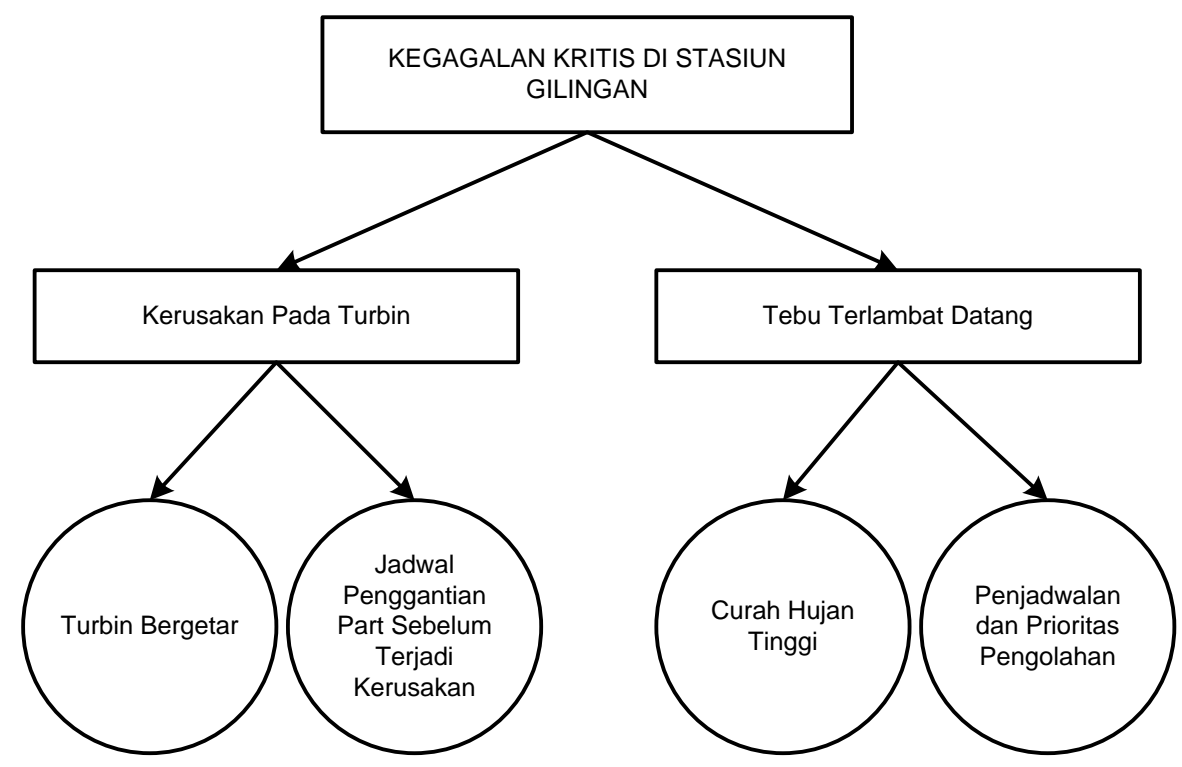

Gambar 1. Fault Tree Kegagalan Kritis di Stasiun Gilingan

Terdapat 4 basic event dari 2 top event yang berada di stasiun gilingan. Basic event tersebut adalah turbin bergetar, jadwal penggantian part sebelum terjadi kerusakan, curah hujan tinggi, serta penjadwalan dan prioritas pengolahan. Kemudian dari hasil penemuan basic event tersebt nantinya akan dicari bagaimana solisi penangananya.

Kerusakan turbin yang ditandai dengan turbin bergetar yaitu disebabkan bearing dan metal sebagai bantalan mengalami korosi adapun penyebab korosi diantaranya yaitu terjadinya over heat (temperatur bantalan naik di atas batas operasional), cincin oli rusak, oli kurang, oli kotor, permukaan bantalan kasar, terdapat kandungan air dalam oli, fibrasi yang berlebihan dari poros, alignment poros yang tidak center. Dari korosi bantalan tersebut berakibat oli tercecer keluar block, dengan nilai RPN 50. Waktu henti akibat dari kerusakan turbin selama 60 menit.

Kedatangan tebu yang terlambat disebabkan oleh faktor cuaca dan jarak tempuh. Curah hujan yang tinggi sangat berpengaruh dalam penebangan dan pengiriman tebu. Sehingga stok tebu dalam pabrik tidak mencukupi dan mengakibatkan tidak ada tebu ampas dapat diperah dengan nilai RPN 45. Keterlambatan tebu hampir pasti terjadi dikarenakan pada periode giling tahun ini cuaca kurang mendukung. Waktu henti akibat dari tebu yang terlambat datang kurang lebih selama 60 menit.

Untuk penanganan basic event turbin bergetar dengan pengecekan berkala mingguan sehingga dapat mengantisipasi terjadinya korosi dan segera melakukan penggantian bantalan. Memastikan bahwa pengecekan dapat berjalan kontinu sehingga jadwal penggantian part sebelum terjadi kerusakan dapat menjadi dokumen yang akurat sehingga dapat menjadi acuan perbaikan berikutnya. Sedangkan basic event tebu terlambat datang dengan mengantisipasi faktor cuaca seperti curah hujan yang tinggi dengan melakukan perbaikan fasilitas penanganan tebu di kebun dan pengangkutannya. Penjadwalan dan prioritas pengolahan perlu dilakukan karena pasokan tebu PG. Jatiroto tidak hanya berasal dari tebu sendiri, tetapi juga dari tebu rakyat. Karena jarak tempuh dari tebu rakyat cukup jauh maka prioritas pengolahan harus diutamakan untuk meminimalisir waktu tunggu di pabrik dan meningkatkan frekuensi kedatangan. 


\section{Simpulan}

Berdasarkan hasil pengolahan data dan analisis yang telah dilakukan dapatdisimpulkan :

a. Terdapat 22 risiko operasional di stasiun gilingan yang berpotensi mengganggu proses produksi di Pabrik Gula Jatiroto.

b. Terdapat dua risiko operasional yang memiliki nilai kritis pada perhitungan RPN, yaitu kerusakan pada turbin dan tebu terlambat datang.

c. Kerusakan pada turbin dan tebu terlambat datang digunakan sebagai top event kemudian dilakukan analisis untuk basic event yang mempengaruhi. Basic event yang didapatkan yaitu turbin bergetar, jadwal penggantian part sebelum terjadi kerusakan, curah hujan tinggi serta penjadwalan dan prioritas pengolahan.

\section{Daftar Pustaka}

Effendi, $\quad$ M. S., Arifin, M. K. 2015.Perbedaan Risk Priority Number Dalam FMEA Sistem Alat Berat Heavy Duty Truck HD 785-7. Spektrum Industri (2015), Vol. 13 No. 1, ISSN : 2442-2630 (Online).

Kristyanto, Raka, dkk. 2013. Analisis Risiko Operasional Pada Produksi Gula Dengan Menggunakan Metode Multi-Attribute Failure Mode Analysis (MAFMA)(Studi Kasus : PG Kebon Agung Malang).Jurnal Rekayasa dan Manajemen Sistem Industri Vol 3 No 3 Teknik Teknik Industri Universitas Brawijaya.

Laricha, Lithrone., Rosehan, Cynthia. 2013. Usulan Perbaikan Kualitas Dengan Penerapan Metode Six Sigma dan Fmea (Failure Mode And Effect Analysis) Pada Proses Produksi Roller Conveyor Mbc di PT XYZ. Jurnal Ilmiah Teknik Industri (2013), Vol. 1 No. 2, 86 - 94.

Puspitasari, Nia Budi., Martanto, Arif. 2014. Penggunaan FMEA Dalam Mengidentifikasi Resiko Kegagalan Proses Produksi Sarung ATM (Alat Tenun Mesin) (Studi Kasus Pt. Asaputex Jaya Tegal). Jurnal Teknik Industri Universitas Dipoegoro (2014) Vol IX, No 2

Pradana, Yana Ayu, Brady Rikumahu. 2014. Penerapan Manajemen Risiko Terhadap Perwujudan Good Corporate Governance Pada Perusahaan Asuransi.Trikonomika (2014)Vol.13, No. 2, Hal.195-204, ISSN 2355-7737 (Online).

Revitasari, C., Novareza, O., Darmawan, Z. 2013. Penentuan Jadwal Preventive Maintenance Mesin-Mesin Di Stasiun Gilingan (Studi Kasus PG. Lestari Kertosono).Jurnal Rekayasa dan Manajemen Sistem Industri Vol 3 No 3 Teknik Teknik Industri Universitas Brawijaya.

Rosih, A. R., Choiri. M., Yuniarti, R. 2013.Analisis Risiko Operasional Pada Departemen Logistik Dengan Menggunakan Metode FMEA. Jurnal Rekayasa dan Manajemen Sistem Industri Vol 3 No 3 Teknik Teknik Industri Universitas Brawijaya.

Sari(2015), Volnah., Djatna,2015. Analisis Strategi Penanganan Risiko Kekurangan Pasokan Pada Industri Pengolahan Rumput Laut (Kasus di Sulawesi Selatan). AGRITECH Vol 35 No. 2. 